\title{
Density of Gr1-positive myeloid precursor cells, p-STAT3 expression and gene expression pattern in canine mammary cancer metastasis
}

\author{
Magdalena Król • Karol M. Pawłowski • \\ Izabella Dolka • Olga Musielak • Kinga Majchrzak • \\ Joanna Mucha • Tomasz Motyl
}

Accepted: 9 June 2011 / Published online: 29 June 2011

(C) The Author(s) 2011. This article is published with open access at Springerlink.com

\begin{abstract}
The very recent studies on human and mice models have indicated an important role of myeloid precursor cells (progenitors or not fully differentiated cells that express the Gr1 antigen also called Gr1-positive myeloid suppressor cells) in the tumor progression and metastasis. They are thought to suppress the immune system and promote angiogenesis via Signal transducer and activator of transcription 3 (STAT3) activation. As of now there is no data available on the correlation of Gr1-positive cell number, phosphorylated STAT3 (p-STAT3) expression and cancer ability to metastasis. Thus, we counted the myeloid precursor cell number and analyzed p-STAT3 expression in 50 canine mammary tumors that gave local/distant metastases and did not metastasize. We showed that the number of Gr1-positive cells and p-STAT3 expression are significantly higher $(p<0.001)$ in the metastatic tumors than in the non-metastatic ones. We also observed higher expression of p-STAT3 in the canine mammary cancer cell lines with metastatic potential than in other cell lines $(p<0.001)$. Moreover, the number of myeloid precursors and p-STAT3 expression in metastatic tumors correlate strongly. The tumor infiltrating myeloid precursor cells may invigorate the STAT3 activity (probably via vascular endothelial growth factor - VEGF) that contributes to the tumor angiogenesis and furthermore tumor's ability to metastasize. The analysis of gene expression in canine mammary cancer cell lines with metastatic potential indicated that semaphorin 3B (SEMA3B) and neuropilin receptors (NRP) may also be important elements in this process. Thus, we discuss the possible interactions within the tumor that may be required for cancer metastatis.
\end{abstract}

M. Król $(\bowtie) \cdot$ K. M. Pawłowski · O. Musielak $\cdot$ K. Majchrzak · J. Mucha · T. Motyl

Department of Physiological Sciences, Faculty of Veterinary Medicine,

Warsaw University of Life Sciences-WULS, Nowoursynowska 159, 02-776 Warsaw, Poland e-mail: magdalena_krol@sggw.pl

K. M. Pawłowski

Department of Animal Environment Biology, Faculty of Animal Sciences,

Warsaw University of Life Sciences-WULS, Ciszewskiego 8, 02-786 Warsaw, Poland

I. Dolka

Department of Pathology and Veterinary Diagnostics, Faculty of Veterinary Medicine,

Warsaw University of Life Sciences - WULS, Nowoursynowska 159, 02-776 Warsaw, Poland 
Keywords Gr1-positive cells $\cdot$ STAT3 $\cdot$ Canine mammary cancer $\cdot$ Metastasis $\cdot$ Angiogenesis

\section{Introduction}

The fact that stromal cells within the tumor undergo various changes during tumor initiation, progression, and metastasis is commonly known. The tumor microenvironment may be composed of various cells, mainly of fibroblasts, newly formed blood vessels as well as hematopoietic cells (Pollard 2008; Król et al. 2011). The interactions between these cells and cancer cells within the tumor lead to rapid and more invigorated tumor growth and metastasis (Liang et al. 2010). How the tumor cells may revert the immune system from performing its antitumor functions to promoting immunosuppression and tumorigenesis is extremely interesting. The regulatory role of myeloid suppressor cells (the cells which express the surface myeloid differentiation antigen $1-\mathrm{Gr} 1$ ) on T cell activity has been only indicated as important by very few recent studies (Dietlin et al. 2007; Kujawski et al. 2010; Liang et al. 2010; Youn and Gabrilovich 2010). Gr1-positive cells from the blood are actively recruited to the tumor microenvironment by various chemokines in the same manner as other cells (for review, see: Gabrilovich and Nagraj 2009; Schmid and Varner 2010). The population comprises a heterogeneous population of bone-marrow-derived myeloid progenitors and immature myeloid cells. Under normal conditions they differentiate into granulocytes, macrophages, or dendritic cells, what helps to explain their heterogeneity (Schmid and Varner 2010; Youn and Gabrilovich 2010). In cancer patients, a partial differentiation block of hematopoietic cells may occur, which results in flourish of these cells into cancer tissue.

The myeloid suppressor cells may also play another role in cancer progression. They promote angiogenesis by production of angiogenic factors such as: vascular endothelial growth factor (VEGF), matrix metalloproteinases (MMPs), and interleukins (ILs). These factors additionally stimulate Gr1-positive cells accumulation in tumors (Voronov et al. 2003; Bunt et al. 2007; Melani et al. 2007; Allavena et al. 2008; Yang et al. 2008; Kujawski et al. 2010).

The role of myeloid precursor cells in tumor angiogenesis was examined by Kujawski et al. (2010). The mice studies have recently shown that this process may be driven by an active Signal transducer and activator of transcription 3 (STAT3). The enhanced angiogenesis correlates with the tumor aptitude to metastasize (Zetter 1998). Kujawski et al. (2010) also showed that the phosphorylated STAT3 (p-STAT3) ablation in experimental mice reduced the number in infiltrating myeloid precursor cells tumor. Although so far the relations between the number of Gr1-positive cells, p-STAT3 expression and the tumor aptitude to metastasis has not been assessed in vivo yet.

Therefore, we have decided to investigate whether the number of Gr1-positive cells and expression of p-STAT3 are associated with the tumor aptitude to metastasize. We have performed immunohistochemical analysis of 50 canine mammary tumors: 40 non-metastatic tumors and 10 tumors that gave local or distant metastases. We also examined p-STAT3 expression in canine mammary cancer cell lines with metastatic potential and in non-metastatic cells. To answer the question how the STAT3 may promote the angiogenesis, the supervised analysis of gene expression in canine mammary cancer cell lines with high metastatic potential was conducted (Król et al. 2010b). The results of this microarray experiment have been partially published (Król et al. 2010b) but for the purposes of this manuscript we analyzed only the unpublished data. We focused on the gene cluster involved in tumor angiogenesis and interactions with hematopoietic cells. 


\section{Materials and methods}

Tissue samples

Tissue sections from canine mammary tumors were obtained from the archives of the Department of Pathology and Veterinary Diagnostics, Faculty of Veterinary Medicine, Warsaw University of Life Sciences - WULS (Poland). The samples were surgically obtained during the mastectomy from 50 female dogs of different breeds. Each tumor sample was fixed in $8 \%$ neutral buffered formalin and routinely embedded in paraffin. The 5 micrometer sticks were fixed on the slides and stained with hematoxylin and eosin (HE) and subjected to the histological evaluation. A wide variety of the patient cases including the information about the presence/absence of metastases is known. The tumors that gave metastases were surgically removed together with the metastatic site. The presence of neoplastic cells in the metastatic site was histologically confirmed. The immunohistochemical examination of cytokeratin, vimentin, smooth muscle actin, s100 protein and p63 protein expression was performed (data not shown). The tumor types of specimens were classified based on the World Health Organization (WHO) Histological Classification and Mammary Tumors of the Dog and Cat classification (Misdorp et al. 1999). Histological tumor grading was conducted on HE-stained sections using a Misdorp (2002) classification. The mammary carcinoma grading was assessed in respect to tubule formation, degree of differentiation and mitotic index as: the 1st, 2nd and 3rd grade of malignancy. All the tumors examined were classified as malignant carcinomas (simple carcinomas or complex carcinomas) or benign adenomas. The types tumors were split into three categories: benign $(n=10)$ and malignant $(n=30)$ non-metastatic (which did not give metastases) and metastatic $(n=10)$ (which gave local or distant metastases). Among the non-metastatic carcinomas 11 were considered as the 1 st grade of malignancy, 9 tumors as the 2nd grade of malignancy, 10 tumors as the 3rd grade of malignancy; the examined 10 metastatic tumors were of the 2 nd and 3 rd grade of malignancy.

\section{Cell lines}

The cell lines used for this study have previously been described in detail (Król et al. 2009; Król et al. 2010a, b; Pawłowski et al. 2011b). Three canine mammary adenocarcinoma cell lines (non-metastatic PL-20, and metastatic CMT-W1, CMT-W2), non-metastatic anaplastic cancer (P114), non-metastatic simple carcinoma (CMT-U27) and non-metastatic spindle-cell mammary tumor (CMT-U309) were examined.

These cell lines were subjected to a detailed cytometric analysis (e.g. cell cycle analysis, ploidy analysis, growth rate assessment and Ki67 expression, Bcl-2 expression, analysis of cells susceptibility to campthotecin-induced apoptosis etc.) (Król et al. 2010b). Based on the results of these analyses they were classified into 3 various phenotypic groups: highly proliferative (P114 and CMT-U27), highly apoptosis-resistant (PL20 and CMT-U27) and metastatic (CMT-W1 and CMT-W2). The detailed results of these analyses have been published (Król et al. 2010b).

Cells were cultured in optimal conditions: a medium (RPMI-1640) enriched with 10\% (v/v) heat-inactivated fetal bovine serum (FBS), penicillin-streptomycin (50 iU mL-1), and fungizone $(2.5 \mathrm{mg} \mathrm{mL}-1)$, in an atmosphere of $5 \% \mathrm{CO} 2$ and $95 \%$ humidified air at $37^{\circ} \mathrm{C}$, and routinely subcultured every second day. The methods of canine mammary cancer cells culturing have been previously described (Król et al. 2009, 2010a, b). 
Immunohistochemistry (IHC)

Five $\mu \mathrm{m}$ sections from paraffin blocks containing tumor tissue were baked in $37^{\circ} \mathrm{C}$ overnight. After dewaxing in xylene and rehydration in ethanol, for antigen retrieval, the slides were placed in $0.02 \mathrm{M}$ citrate buffer, $\mathrm{pH} 6.0$ and boiled in the decloaking chamber.

The cell lines were cultured on Lab-Tek (Nunc Inc. USA) 4-chamber culture slides and subjected to the immunohistochemical analysis were fixed with ethanol after the $24 \mathrm{hrs}$.

The samples were incubated in the Peroxidase Blocking Reagent (Dako, Denmark) for $10 \mathrm{~min}$ at room temperature prior to the antibody incubation. After $30 \mathrm{~min}$ incubation in 5\% bovine serum albumin (Sigma Aldrich, Germany), the following primary antibodies were used (diluted in 1\% bovine serum): rat monoclonal anti-Gr1 (in case of paraffin slides) and rabbit polyclonal STAT3 (phospho S727) (for paraffin slides and cell lines) both obtained from Abcam (United Kingdom). According to the manufacturer's instructions the slides were incubated with antibodies at $+4^{\circ} \mathrm{C}$ overnight. For the staining the anti-rat rabbit polyclonal antibodies Horseradish peroxidase (HRP)-conjugated (Abcam) and EnVision kit (Labelled Polymers consist of secondary anti-rabbit antibodies conjugated with the HRP enzyme complex obtained from Dako) were used. To develop the colored product, the 3,3 'Diaminobenzidine (DAB) substrate was used (Dako). Finally, the hematoxyline was used for nuclei counterstaining.

For each immunohistochemical experiment of paraffin slides, two controls (negative and positive) were used: as a positive control the tissues of canine lymph nodes (in case of Gr1 antibodies) and normal mammary tissue (in case of anti-STAT3 antibodies), whereas the negative control were stained without use of primary antibodies. For each immunohistochemical analysis of cell lines the negative control was used (the staining procedure without use of primary antibodies).

Three consecutive tissue sections and four slides of each cell line were analyzed. The 10-20 pictures of each slide were taken (depending on the sample size) using Olympus microscopy BX60. In the case of the tissues only the regions of cancer cells and stroma were analyzed, the tumor necrosis regions were avoided. The number of Gr1-positive cells (brown color) and the colorimetric intensity of the p-STAT3 expression reflected as IHCstained antigen spots (brown color) were counted by a computer-assisted image analyzer (Olympus Microimage ${ }^{\mathrm{TM}}$ Image Analysis, software version 4.0 for Windows, USA). The antigen spot color intensity is expressed as a mean pixel optical density on a 1-256 scale.

Gene expression analysis

RNA from the cell suspension samples was isolated using a Total RNA kit (A\&A Biotechnology, Poland) according to the manufacturer's protocol. The quantity and quality of isolated RNA was measured using BioAnalyzer (Agilent, USA). Equal amounts of RNA isolated from all examined cell lines were pooled and used as the experiment control.

For each microarray slide, total RNA $(10 \mu \mathrm{g})$ of each cell line was reverse-transcribed using SuperScript Plus Direct cDNA Labeling System, (Invitrogen, USA) according to the manufacturer's protocol. Single-strand cDNAs were stained with Alexa 647 and Alexa 555 (Invitrogen). Dog-specific oligonucleotide microarray slides Canis familiaris V1.0.1 AROS (Operon, USA) with 25,383 probes were used for the hybrydization. Hybridization was performed using automatic hybridization station HybArray12 (PerkinElmer, USA). Two replicates were performed (dye-swap). 
The slides were analyzed using microarray scanner ScanArray HT and ScanExpress software (PerkinElmer, USA). The data was automatically normalized (LOWESS method) by ScanExpress software. The average ratio of 2 slides was calculated.

The part of these microarray results has been previously published, thus the detailed methodology has been previously described (Król et al. 2010b). The results of the microarray experiment has been also validated using real-time qPCR (Król et al. 2010b).

Statistical analysis

The IHC statistical analysis was conducted using Prism version 5.00 software (GraphPad Software, USA). The ANOVA and Tukey Honestly Significant Difference (HSD) post-hoc tests were applied to analyze the number of myeloid precursor cells and p-STAT3 density in all the examined tumor sub-groups as well as in the examined cell lines. To assess the correlation between the number of Gr1-positive cells and p-STAT3 expression in nonmetastatic and metastatic groups the Pearson correlation coefficient was used and $\mathrm{r}^{2}$ was calculated. The $p<0.05$ was regarded as significant whereas $p<0.001$ as highly significant.

The microarray data was analyzed with SAM software (Statistical Analysis of Microarrays; Stanford University, USA). The list of genes differing significantly in expression was generated with a false discovery rate (FDR) of $<5 \%$. Genes in which expression changed at least 1.3 -fold in each of 2 examined slides were subjected to further analysis (this analysis has been previously accounted for, see: Król et al. 2010b). The gene function was identified using the NCBI database, PANTHER pathway analysis software (Mi et al. 2005) and Architect Pathway software (Agilent, USA). The pathway analyses were conducted using binominal statistic test (PANTHER) with the cut-off value $p<0.05$.

\section{Results}

Tumor samples analysis

The analysis showed that the number of Gr1-positive cells is significantly higher $(p<0.001)$ in the tumors that gave local or distant metastases comparing to the non-metastatic carcinomas or adenomas $(68.58 \pm 30.96,7.908 \pm 1.099$ and $2.08 \pm 0.36$, respectively) (Fig. 1a, b). The malignancy-related to tendency increase regarding the number of myeloid precursor cells was observed in the group of all non-metastatic tumors (increasing from benign to the most malignant), however no significant differences between these groups have been observed (Fig. 1a, b; Table 1). Gr1-positive cells constituted a heterogeneous population observed rather as the cell "niches" than the single cells.

The expression of p-STAT3 was detected in cancer cells (cytoplasmic staining pattern) and also in hematopoietic cells however not in the other stromal cells. Significantly higher expression $(p<0.001)$ of this antigen was found in the metastatic tumors than in the nonmetastatic carcinomas or adenomas $(146.0 \pm 2.37,115.6 \pm 1.726$ and $118.1 \pm 4.0$, respectively) (Fig. 2a, b). The p-STAT3 expression was equally intense in the all non-metastatic tumors, without any significant differences between benign adenomas and carcinomas of various grade of malignancy (Fig. 2a, b; Table 1).

To assess the correlation between the number of Gr1-positive cells and p-STAT3 expression in the metastatic and non-metastatic groups the Pearson correlation coefficient was used. The high correlation between the number of Gr1-positive cells and p-STAT3 expression in metastatic tumors was detected $\left(r^{2}=0.73, p<0.05\right)$. No significant relation between the number of Gr1- 
a

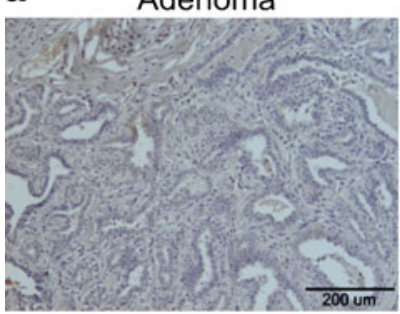

Carcinoma 3rd G

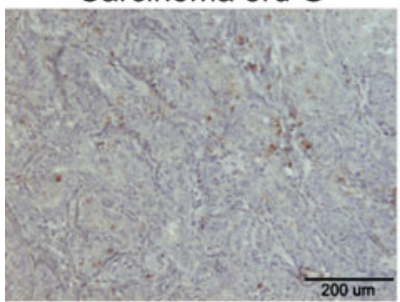

Carcinoma 1st G

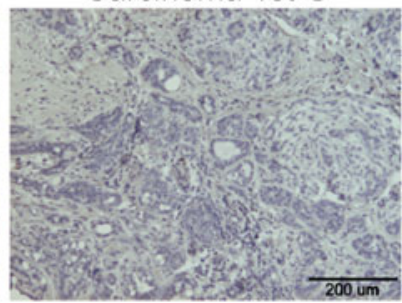

Metastatic carcinoma

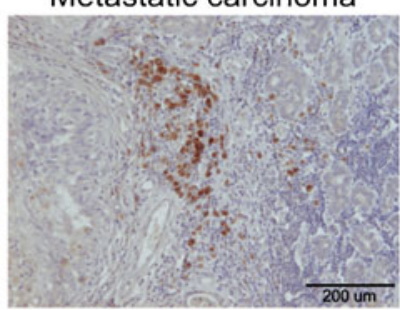

Carcinoma 2nd G

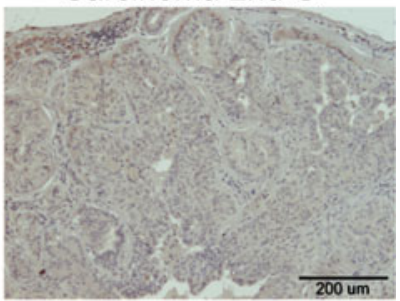

b

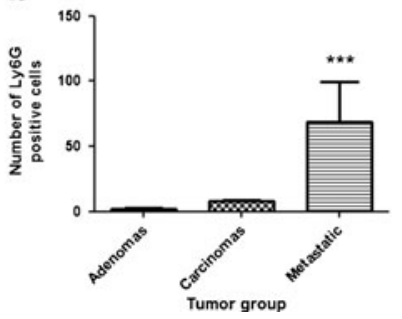

Fig. 1 a Pictures of Gr1-positive cells in canine mammary adenomas, carcinomas of the 1st, 2nd, 3rd grade of malignancy and tumors that gave local/distal metastases $(n=50)$ obtained with Olympus BX60 microscope (at the magnification of 200x). The Gr1 antigen is represented by brown colored structures. b The graph of number of Gr1-positive cells (and SD) in canine mammary non-metastatic adenomas, carcinomas and metastatic carcinomas. Ten to 20 pictures in each slide were analyzed (three consecutive sections). The number of objects was counted by a computer-assisted image analyzer (Olympus Microimage ${ }^{\mathrm{TM}}$ Image Analysis, software version 4.0 for Windows, USA). The statistical analysis was performed using Prism version 5.00 software (GraphPad Software, USA). The ANOVA and Tukey HSD (Honestly Significant Difference) post-hoc test were applied to analyze the number of myeloid precursor cells in all the examined tumor groups. $p<0.001$ was regarded as highly significant and marked as $* * *$

positive cells and p-STAT3 expression was detected neither in the non-metastatic carcinomas $\left(r^{2}=0.263, p<0.186\right)$ nor in the non-metastatic adenomas $\left(r^{2}=-0.197, p<0.585\right)$.

p-STAT3 expression in the examined cell lines

The expression of p-STAT3 was detected in all the examined cell lines, they however differed in the staining pattern. In the cell lines that did not give metastases the cytoplasmic staining pattern was observed (Fig. 3a), whereas in metastatic CMT-W1 and CMT-W2 cell lines the p-STAT3 expression was detected in cytoplasm and nuclei (Fig. 3b). Significantly higher expression $(p<0.001)$ of this antigen was detected in the metastatic cell lines than in the non-metastatic ones $(142.2 \pm 2.43$ and $110.9 \pm 2.73$, respectively) (Fig. 3a, b, c). The

Table 1 The number of Gr1-positive cells and p-STAT3 expression in canine mammary non-metastatic adenomas and adenocarcinomas of the $1 \mathrm{st}$, 2nd and 3rd grade of malignancy and in the group of tumors that gave local or distal metastases. Results are presented as means $\pm \mathrm{SD}$

\begin{tabular}{lccccc}
\hline & $\begin{array}{l}\text { Adenoma } \\
(n=10)\end{array}$ & $\begin{array}{l}\text { Carcinoma of } \\
\text { the 1st grade } \\
(n=11)\end{array}$ & $\begin{array}{l}\text { Carcinoma of } \\
\text { the 2nd grade } \\
(n=9)\end{array}$ & $\begin{array}{l}\text { Carcinoma of } \\
\text { the 3rd grade } \\
(n=10)\end{array}$ & $\begin{array}{l}\text { Metastatic } \\
\text { tumors } \\
(n=10)\end{array}$ \\
\hline Gr1 cells & $2.08 \pm 1.2$ & $4.86 \pm 5.59$ & $6.17 \pm 2.33$ & $12.7 \pm 5.44$ & $68.58 \pm 30.96$ \\
p-STAT3 & $118.1 \pm 12.65$ & $111.5 \pm 8.2$ & $115.9 \pm 11.06$ & $120,04 \pm 6.9$ & $146.0 \pm 2.37$ \\
\hline
\end{tabular}


a

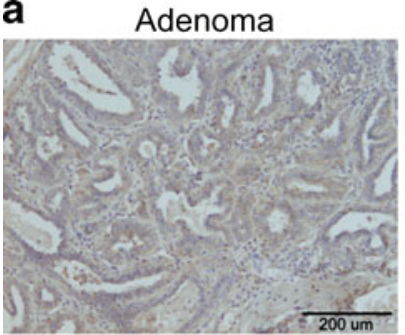

Carcinoma 3rd G

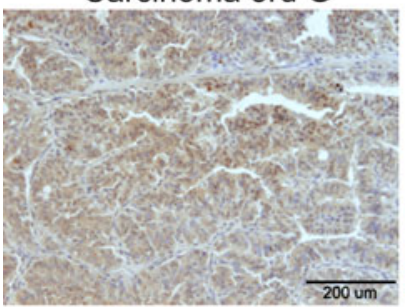

Carcinoma 1st G

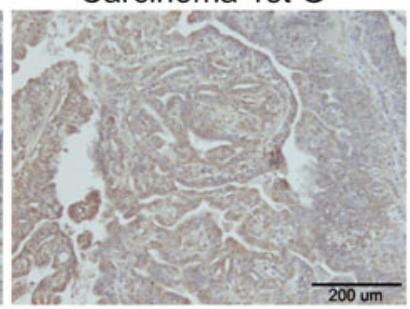

Metastatic carcinoma

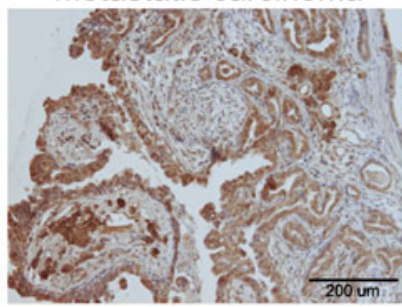

Carcinoma 2nd G

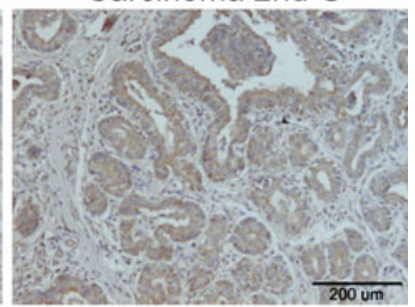

b

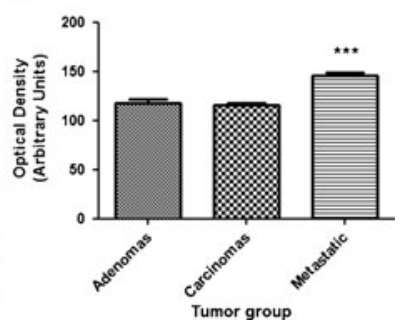

Fig. 2 a Pictures of p-STAT3 in canine mammary adenomas, carcinomas of the 1st, 2nd, 3rd grade of malignancy and tumors that gave local/distal metastases $(n=50)$ obtained using Olympus BX60 microscope (at the magnification of 200x). The p-STAT3 is reflected as brown color. b The graph of mean optical density of p-STAT3 (and SD) in canine mammary non-metastatic adenomas, carcinomas and metastatic carcinomas. Ten to 20 pictures in each slide were analyzed (three consecutive sections). The colorimetric intensity of the IHC-stained antigen spots was counted by a computer-assisted image analyzer (Olympus Microimage ${ }^{\text {TM }}$ Image Analysis, software version 4.0 for Windows, USA) and the antigen spot color intensity is expressed as mean pixel optical density on a 1-256 scale. The statistical analysis was performed using Prism version 5.00 software (GraphPad Software, USA). The ANOVA and Tukey HSD (Honestly Significant Difference) posthoc tests were applied to analyze the optical density in all the examined tumor groups. $p<0.001$ was regarded as highly significant and marked as $* * *$

a

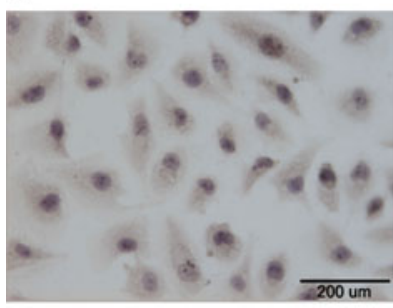

b

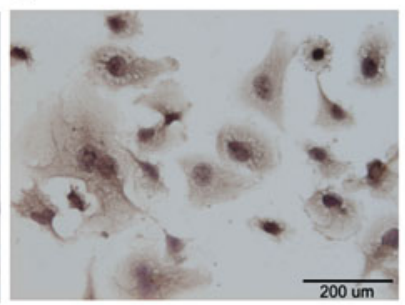

C

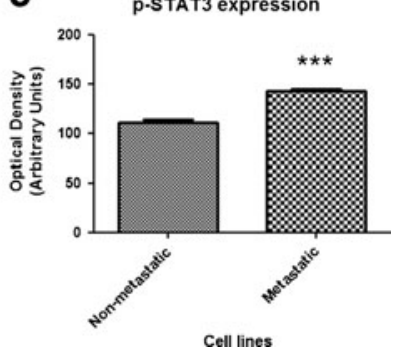

Fig.3 a Representative picture of p-STAT3 in non-metastatic canine mammary cancer cell line (CMT-U309) obtained using Olympus BX60 microscope (at the magnification of 200x). The p-STAT3 is reflected as brown color. b Representative picture of p-STAT3 in canine mammary cell line (CMT-W1) with high metastatic potential obtained using Olympus BX60 microscope (at the magnification of 200x). The p-STAT3 is reflected as brown color. $\mathbf{c}$ The graph of mean optical density of p-STAT3 (and SD) in canine mammary non-metastatic (CMT-U27, CMT-U309, P114 and PL20) and metastatic (CMT-W1 and CMT-W2) cancer cell lines. Ten pictures in each slide were analyzed. The colorimetric intensity of the IHC-stained antigen spots was counted by a computer-assisted image analyzer (Olympus Microimage ${ }^{\mathrm{TM}}$ Image Analysis, software version 4.0 for Windows, USA) and the antigen spot color intensity is expressed as mean pixel optical density on a 1-256 scale. The statistical analysis was performed using Prism version 5.00 software (GraphPad Software, USA). The unpaired t-test was applied to analyze the optical density in non-metastatic versus metastatic cell lines. $p<0.001$ was regarded as highly significant and marked as *** 
p-STAT3 expression intensity was similar in all the non-metastatic cell lines, without any significant differences between them (ranging from 107.6 \pm 4.39 to $117.0 \pm 3.77$ ). The values of optical density related to the p-STAT3 expression in the examined cell lines were very similar to these reported on tumors.

\section{Gene expression analysis}

The microarray experiment revealed a group of significantly up-regulated genes (FDR $<5 \%$, fold change $>1.3$ ) in each of the cell line (Król et al. 2010b).

For the purposes of this manuscript we run a supervised analysis of the unpublished results of genes up-regulated in CMT-W1 and CMT-W2 metastatic cell lines to find genes involved in angiogenesis and interactions with hematopoietic cells.

The microarray analysis revealed the significant up-regulation of 73 and 102 genes in CMT-W1 and CMT-W2 cell lines, respectively (Król et al. 2010b). The PANTHER ontological analysis revealed significant up-regulation of 9 and 7 genes in CMT-W1 and CMT-W2 cell lines, respectively, involved in angiogenesis and interactions with hematopoietic cells (Tables 2 and 3). The PANTHER statistical pathway analysis revealed up-regulation of significantly higher number $(p<0.05)$ of genes involved in angiogenesis, cytokine/chemokine mediated signaling pathway, and interferon-gamma signaling pathway (Table 4) in metastatic cell lines than in the other examined cell lines.

In both metastatic cell lines the up-regulation of semaphorin 3B (SEMA3B), which is directly involved in angiogenesis, was observed. The neuropilin receptor 1 up-regulation in CMT-W1, and neuropilin receptor 2 up-regulation in CMT-W2 cell line were also observed. Relying on current and prior studies we suppose that, the activity of these genes may correlate with the STAT3 regarding angiogenesis pathway.

\section{Discussion}

As of now there are many papers available on canine mammary tumors examined at different levels: from genes to proteins (Rao et al. 2009; Badowska-Kozakiewicz and Malicka 2010; Król et al. 2010a and b; Pawłowski et al. 2009, 2011a and b) but there are only few on the canine tumor microenvironment. The available literature focuses on the angiogenesis in canine mammary tumors (Restucci et al. 2002; Jakab et al. 2008; Qui et al. 2008) or the role of MMPs in tumorigenesis (Hirayama et al. 2002; Papparella et al. 2002; Kawai et al. 2006). Our previous study (Król et al. 2011) was the first to give an account of the relation between tumor-associated macrophages (TAMs) density and tumor ability to metastasize. Although the role of macrophages, lymphocytes or other stromal cells in tumor progression is commonly known, the possible impact of bone marrow derived suppressor cells on tumor progression and metastasis is still unclear (Voronov et al. 2003; Yang et al. 2004 and 2008; Jodele et al. 2005; Bunt et al. 2007, Allavena et al. 2008) just as mechanisms of increasing the rate of tumor angiogenesis.

Thus, we analyzed the number of myeloid suppressor cells (Gr1-positive) in 50 canine mammary tumors. The myeloid differentiation antigen Gr1 is thought to be expressed on the myeloid lineage precursor cells which was also confirmed by our results. This surface marker used for the identification of myeloid suppressor cells is common for several populations of myeloid precursors. There is no agreement between various investigators as to which proteins should be treated as markers of different subsets of myeloid derived suppressor cells in human and mice (Bronte et al. 2000; Almand et al. 2001; Mazzoni et al. 


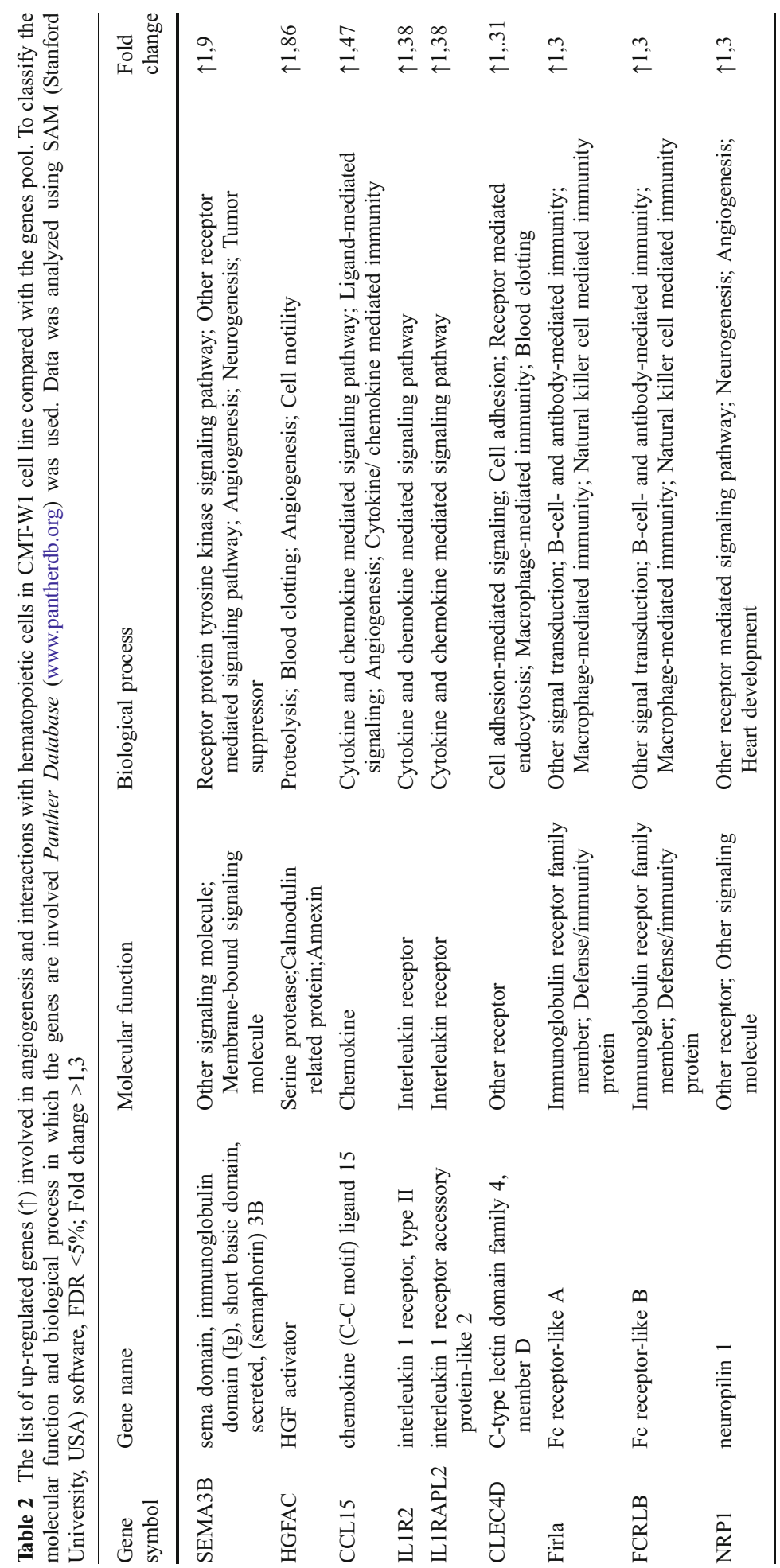


Table 3 The list of up-regulated genes ( $\uparrow$ ) involved in angiogenesis and interactions with hematopoietic cells in CMT-W2 cell line compared with the genes pool. To classify the molecular function and biological process in which the genes are involved Panther Database (www.pantherdb.org) was used. Data was analyzed using SAM (Stanford University, USA) software, FDR $<5 \%$; Fold change $>1,3$

\begin{tabular}{|c|c|c|c|c|}
\hline $\begin{array}{l}\text { Gene } \\
\text { symbol }\end{array}$ & Gene name & Molecular function & Biological process & $\begin{array}{l}\text { Fold } \\
\text { change }\end{array}$ \\
\hline CCL13 & $\begin{array}{l}\text { chemokine (C-C motif) } \\
\text { ligand } 13\end{array}$ & Chemokine & $\begin{array}{l}\text { Cytokine and chemokine } \\
\text { mediated signaling pathway; } \\
\text { Ligand-mediated signaling; } \\
\text { Cytokine/chemokine mediated } \\
\text { immunity }\end{array}$ & $\uparrow 2,2$ \\
\hline CNTN1 & contactin 1 & $\begin{array}{l}\text { CAM family } \\
\text { adhesion molecule }\end{array}$ & Cell adhesion; Neurogenesis & $\uparrow 1,53$ \\
\hline ECE2 & $\begin{array}{l}\text { endothelin converting } \\
\text { enzyme } 2\end{array}$ & Metalloprotease & $\begin{array}{l}\text { Proteolysis; Cell surface receptor } \\
\text { mediated signal transduction; } \\
\text { Cell communication; } \\
\text { Regulation of vasoconstriction, } \\
\text { dilation; Other homeostasis } \\
\text { activities }\end{array}$ & $\uparrow 1,52$ \\
\hline NRP2 & neuropilin 2 & $\begin{array}{l}\text { Other receptor;Other } \\
\text { signaling molecule }\end{array}$ & $\begin{array}{l}\text { Other receptor mediated signaling } \\
\text { pathway;Neurogenesis; } \\
\text { Angiogenesis; } \\
\text { Heart development }\end{array}$ & $\uparrow 1,42$ \\
\hline HSPG2 & $\begin{array}{l}\text { heparan sulfate proteoglycan } \\
2 \text { (perlecan) }\end{array}$ & Extracellular matrix & $\begin{array}{l}\text { Cell adhesion-mediated signal- } \\
\text { ing; Extracellular matrix } \\
\text { protein-mediated signaling; } \\
\text { Cell adhesion }\end{array}$ & $\uparrow 1,34$ \\
\hline IFI44L & $\begin{array}{l}\text { interferon-induced protein } \\
\text { 44-like }\end{array}$ & $\begin{array}{l}\text { Molecular function } \\
\text { unclassified }\end{array}$ & Biological process unclassified & $\uparrow 1,32$ \\
\hline SEMA3B & $\begin{array}{l}\text { sema domain, } \\
\text { immunoglobulin domain } \\
\text { (Ig), short basic domain, } \\
\text { secreted, (semaphorin) 3B }\end{array}$ & $\begin{array}{l}\text { Other signaling } \\
\text { molecule; } \\
\text { Membrane-bound } \\
\text { signaling molecule }\end{array}$ & $\begin{array}{l}\text { Receptor protein tyrosine kinase } \\
\text { signaling pathway; Other } \\
\text { receptor mediated signaling } \\
\text { pathway; Angiogenesis; } \\
\text { Neurogenesis; Tumor } \\
\text { suppressor }\end{array}$ & $\uparrow 1,3$ \\
\hline
\end{tabular}

2002, Huang et al. 2006), thus it is probably not feasible to clearly determine their subgroups using immunohistochemical staining of tumor tissues. But all the authors have agreed that their immune suppressive functions (although at different level between the cell subsets) can be identified by the level of Gr1 expression (Kusmartsev et al. 2000; Dietlin et al. 2007; Youn and Gabrilovich 2010).

Thus, we examined the expression of the whole Gr1-positive myeloid suppressor cells set in the canine mammary cancer tissues. We classified Gr1-positive cells as a wider group of various myeloid precursor cells that shows the suppressive features. So far it was mainly assessed in the experimental mice models as much as in various in vitro conditions but not in domestic animals. This study showed that the Gr1-positive cells in canine mammary tumors formed the morphologically heterogenous population. We showed that the number of Gr1-positive cells is noticeably higher $(p<0.001)$ in the metastatic tumors, whereas no significant differences were observed between neither non-metastatic adenomas and carcinomas nor non-metastatic malignant tumors of the various grade of malignancy (Fig. 1, Table 1). 
Table 4 The list of over-represented cellular pathways of PANTHER classification categories in CMT-W1 and CMT-W2 cell lines in comparison to the other cells lines used in this study. The binomial test for each PANTHER pathway was used $(p<0.05)$

Metastatic CMT-W1 and CMT-W2 cell lines

Angiogenesis

Cytokine/chemokine mediated signaling pathway

Interferon-gamma signaling pathway

FGF signaling pathway

Serine glycine biosynthesis

Noch signaling pathway

Glycolysis
Non-metastatic cell lines used in this study

Heterotrimeric G-protein signaling pathway PDGF signaling pathway

Ubiquitin proteasome

RNA spliceing

EGF receptor signaling pathway

Blood coagulation

Oxidative stress response

Based on Kujawski et al. (2010) results suggesting the possible crosslink between myeloid suppressor cells and STAT3 and its contribution to angiogenesis we examined the p-STAT3 expression in canine mammary tumor tissues. We detected significantly higher $(p<0.001)$ expression of p-STAT3 in metastatic tumors than in non-metastatic tumors (Fig. 2, Table 1). The p-STAT3 expression was observed not only in cancer cells, but also in the stromal hematopoietic cells. Similar results were obtained by Kujawski et al. (2010) using mouse systems and human breast cancer tissues. We also showed that the number of myeloid precursor cells and p-STAT3 expression in metastatic tumors correlate highly $\left(\mathrm{r}^{2}=0.73\right.$; $p<0.05$ ), whereas in non-metastatic carcinomas or adenomas the significant correlation between Gr1-positive cells and p-STAT3 expression has not been observed. It means that the level of p-STAT3 expression in metastatic tumors was not risen only because of the higher number of myeloid precursor cells but also due to its higher expression in the cancer cells.

We also observed a significantly higher $(p<0.001)$ expression of p-STAT3 in metastatic canine mammary cancer cell lines than in non-metastatic cell lines (Fig. 3).

The genesis of metastasis has not been fully accounted for. However the extensive studies in this field provide ever more information about associated mechanisms. One of the factors that contributes to tumor metastasis is the myeloid precursor cells infiltration. The STAT3 is a negative regulator of hematopoiesis. Its ablation in hematopoietic cells results in e.g. increased numbers of matured granulocytes (Lee et al. 2002; Kortylewski et al. 2005; Panopoulous et al. 2006; Kujawski et al. 2010). Thus, its higher expression may be one of the factors that partially block the bone-marrow-derived cells differentiation in patients with cancer that leads to a spread myeloid precursor cells in cancer tissue (Schmid and Varner 2010). Since the p-STAT3 expression has also been observed in hematopoietic cells within the tumor we assume the autocrine signaling may also occur. These tumor-infiltrating myeloid precursors enhance angiogenesis by secretion of various angiogenic factors (Voronov et al. 2003; Bunt et al. 2007; Melani et al. 2007; Allavena et al. 2008; Yang et al. 2008; Kujawski et al. 2010). On the other hand, STAT3 contributes to angiogenesis not only by enhancing the Grl-positive cells accumulation per se but also by increasing the angiogenic factors secretion by Gr1-positive cells and tumor cells as well (Kujawski et al. 2010), being the most important angiogenesis inducers VEGF (Zhao et al. 2011). Some studies give evidence of STAT3 and VEGF correlation in angiogenesis. Suppression of STAT3 reduces the VEGF expression in various cancers, identifying STAT3 as a target of antiangiogenic therapy (Niu et al. 2002; Zhao et al. 2011). Bartoli et al. (2003) has showed that VEGF promotes rapid phosphorylation of STAT3 which is then paired with VEGF receptor (VEGFR). The STAT3/VEGFR complex stimulates the VEGF autocrine expression (Fig. 4). 


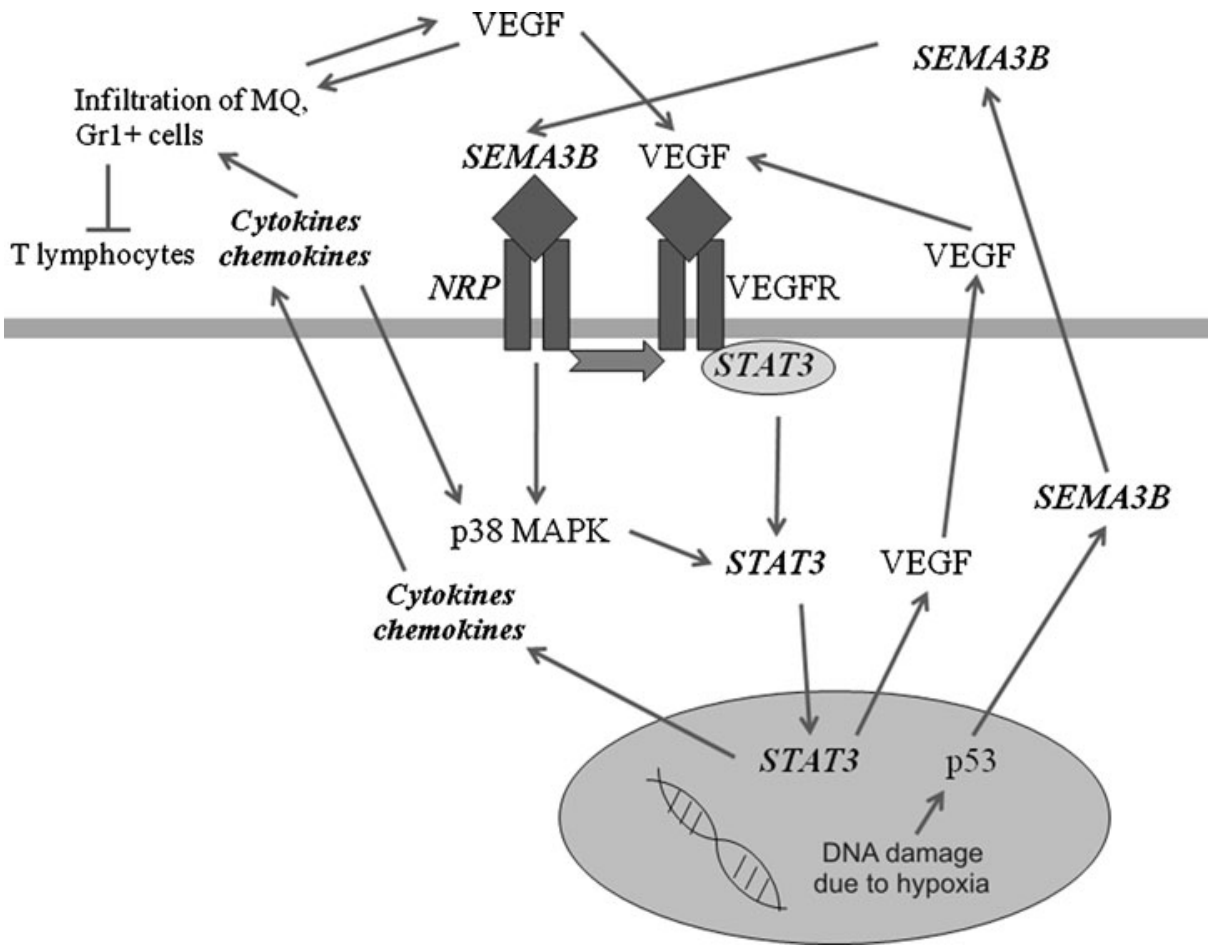

Fig. 4 The scheme of possible interactions between the up-regulated genes in canine mammary metastatic cell lines, STAT3 and hematopoietic cells. The names of the identified in microarray study genes and STAT3 were bolded and written in italic. The arrows indicate the activation. The bar-headed line indicates inhibition. The explanation of abbreviations: Gr1+ cells - myeloid precursor cells that express Gr1 antigen; MQ - macrophages; NRP - neuropilin receptor; p38MAPK - p38 mitogen activated protein kinase; p53 - p53 gene; SEMA3B semaphorin 3B; STAT3 - Signal transducer and activator of transcription 3; VEGF - vascular endothelial growth factor; VEGFR - vascular endothelial growth factor receptor. The graph was made in Corel Photo Paint 3.0 (by Corel Draw, USA)

Two of the up-regulated genes in metastatic cell lines: NRP and SEMA3B are also directly involved in this process (Tables 2 and 3). SEMA3B binds to the NRP forming a complex with VEGFR (as neurophilins are co-receptors for VEGF) and having positive effect on VEGF/NRP-driven vascular development (Gu et al. 2003). NRP may also increase VEGF affinity toward VEGFR (Potrion et al. 2003). The SEMA3B increases p38 mitogen activated protein kinase (p38 MAPK) activity in the cell, which induces VEGF expression via STAT3 (Wang et al. 2007). It also increases cytokines/chemokines secretion from tumor cells (via STAT3) what leads to macrophage infiltration (Potrion et al. 2003) and angiogenesis promotion (Fig. 4). Moreover, Jung et al. (2001) showed that cytokines may increase VEGF synthesis by the same mechanism as SEMA3B (via p38 MAPK and STAT3) (Fig. 4). SEMA3B is activated by the p53 protein during DNA damage or as a stress response (e.g. hypoxia, the main factor leading to increased angiogenesis).

Our microarray study also showed a few chemokines, interferon and interleukin receptors expression (chemokine $\mathrm{C}-\mathrm{C}$ motif ligand 13 and 15, interleukin 1 receptor 2, interleukin 1 receptor accessory protein-like 2, interferon-induced protein 44-like) in metastatic cell lines in comparison to the non-metastatic cells (Tables 3 and 4). Both interferon and interleukins also activate STAT3 (Yang et al. 1998; Lee et al. 2006). 
The other mechanism by which myeloid suppressor cells contribute to cancer progression is the immune system depletion via regulation of T cell activity (Kusmartsev et al. 2000; Dietlin et al. 2007). Estrela-Lima et al. (2010) showed that in the canine mammary metastatic tumors the infiltration of a whole population of $\mathrm{T}$ lymphocytes is significantly lower than in non-metastatic tumors. Thus, it is possible that myeloid suppressor cells accumulation in metastatic tumors may decrease the $\mathrm{T}$ lymphocytes number and contribute to the tumor progression and metastasis by those means (Fig. 4). It is possible that myeloid precursor cells can also activate other critical oncogenic pathways for metastatic process henceforth further studies in this field are crucial.

Relying on presented results and literature available we conclude, that STAT3 seems to play a crucial role in the angiogenic pathway (Fig. 4). Our results regarding p-STAT3 expression in canine mammary cancer cell lines cultured in vitro and depletion of all the hematopoietic/stromal cell signals may indicate, that the individual predisposition of cancer cell to STAT3 activation could begin the further cascade which leads to angiogenesis and metastasis: block of myeloid-derived cells differentiation, their tumor infiltration, lymphocyte $\mathrm{T}$ inhibition, angiogenesis promotion via VEGF, SEMA3B and cytokines production what also leads to macrophage accumulation and metastasis (Fig. 4). This immature and as of yet rather preliminary working hypothesis needs further investigation.

Acknowledgments This work was supported by grants no N N308012939 and N N308230536 from Ministry of Sciences and Higher Education. This work was performed by financial support of the Foundation for Polish Science (Start stipendium and Parent-Bridge program). The authors would like to thank Dr. Eva Hellmen, Dr. Gerard Rutteman, Prof. Dr. Maciej Ugorski and Dr. Joanna Polańska for their kind donation of the examined cell lines. The experiments comply with the current laws of Poland. The authors declare that they have no conflict of interest.

Open Access This article is distributed under the terms of the Creative Commons Attribution Noncommercial License which permits any noncommercial use, distribution, and reproduction in any medium, provided the original author(s) and source are credited.

\section{References}

Allavena P, Sica A, Solinas G, Porta C, Mantovani A (2008) The inflammatory micro-environment in tumor progression: the role of tumor-associated macrophages. Crit Rev Oncol Hematol 66:1-9

Almand B, Clark JI, Nikitina E, van Baynen J, English NR, Knight SC, Carbone DP, Gabrilovich DI (2001) Increased production of immature myeloid cells in cancer patients: a mechanism of immunosuppresion in cancer. J Immunol 166:678-689

Badowska-Kozakiewicz AM, Malicka E (2010) Expression of cyclooxygenase-2 in neoplasms od the mammary gland in bitches. Pol J Vet Sci 13:337-342

Bartoli M, Platt D, Lemtalasi T, Gu X, Brooks SE, Marrero MB, Caldwell RB (2003) VEGF differentially activates STAT3 in microvascular endothelial cells. FASEB J 17:1562-1564

Bronte V, Apolloni E, Cabrelle A, Ronca R, Serafini P, Zamboni P, Restifo NP, Zanovello P (2000) Identification of CD11b+/Gr-1+/CD31+ myeloid progenitor capable of activating or suppressinf CD8+ T cells. Blood 96:3838-3846

Bunt SK, Yang L, Sinha P, Clements VK, Leips J, Ostrand-Rosenberg S (2007) Reduced inflammation in the tumor microenvironment delays the accumulation of myeloid-derived suppressor cells and limits tumor progression. Cancer Res 67:10019-10026

Dietlin TA, Hofman FM, Lund BT, Gilmore W, Stohlman SA, van der Veen RC (2007) Mycobacteria-induced Gr-1+ subsets from distinct myeloid lineages have opposite effect on T cell expansion. J Leukoc Biol 81:1205-1212

Estrela-Lima A, Araujo MS, Costa-Neto JM, Teixeira-Carvalho A, Barrouin-Melo SM, Cardoso SV, Martins-Filho OA, Serakides R, Cassali GD (2010) Immunophenotypic features of tumor infiltrating lymphocytes from mammary carcinomas in female dogs associated with prognostic factors and survival rates. BMC Cancer 10:256 
Gabrilovich DI, Nagraj S (2009) Myeloid-derived-supressor cells as regulators of the immune system. Nat Rev Immunol 9:162-174

Gu C, Rodriguez ER, Reimert DV, Shu T, Fritzch B, Richards LJ (2003) Neuropilin-1 conveys semaphoring and VEGF signaling during neural and cardiovascular development. Dev Cell 5:45-57

Hirayama K, Yokota H, Onai R, Kobayashi T, Kumata T, Kihara K, Okamoto M, Sako T, Nakade T, Izumisawa Y, Taniyama H (2002) Detection of matrix metalloproteinases in canine mammary tumors: analysis by immunohistochemistry and zymography. J Comp Pathol 127:249-256

Huang B, Pan PY, Li Q, Sato AI, Levy DE, Bromberk J, Divino CM, Chen SH (2006) Gr-1+CD115+ immature myeloid suppressor cells mediate the development of tumor-induced $\mathrm{T}$ regulatory cells and $\mathrm{T}-$ cell anergy in tumor-bearing host. Cancer Res 66:1123-1131

Jakab C, Halasz J, Kiss A, Schaff Z, Szasz AM, Rusvai M, Abonyi Toth Z, Kulka J (2008) Evaluation of microvessel density (MVD) in canine mammary tumours by quantitative immunohistochemistry of the claudin-5 molecule. Acta Vet Hung 56:495-510

Jodele S, Chantrain CF, Blavier L, Lutzko C, Crooks GM, Shimada H, Coussens LM, DeClerck YA (2005) The contribution of bone marrow-derived cells to the tumor vasculature in neuroblastoma is matrix metalloproteinase-9 dependent. Cancer Res 65:3200-3208

Jung YD, Liu W, Reinmuth N, Ahmad SA, Fan F, Gallick GE, Ellis LM (2001) Vascular endothelial growth factor is upregulated by interleukin-1 beta in human vascular smooth muscle cells via the p38 mitogenactivated protein kinase pathway. Angiogenesis 4:155-162

Kawai K, Uetsuka K, Doi K, Nakayama H (2006) The activity of matrix metalloproteinases (MMPs) and tissue inhibitors of matalloproteinases (TIMPs) in mammary tumors of dogs and rats. J Vet Med Sci 68:105-111

Kortylewski M, Kujawski M, Wang T, Wei S, Zhang S, Pilon-Thomas S, Niu G, Kay H, Mule J, Kerr WG, Jove R, Pardoll D, Yo H (2005) Inhibiting Stat3 signaling in the hematopoietic system elicits multicomponent antitumor immunity. Nat Med 11:1314-1321

Król M, Pawłowski KM, Skierski J, Rao NAS, Hellmen E, Mol JA, Motyl T (2009) Transcriptomic profile of two canine mammary cancer cell lines with different proliferative and anti-apoptotic potential. J Physiol Pharmacol 60:95-106

Król M, Polańska J, Pawłowski KM, Skierski J, Majewska A, Ugorski M, Motyl T (2010a) Molecular signature of cell lines isolated from mammary adenocarcinoma metastases to lungs. J Appl Genet 51:37-50

Król M, Pawłowski KM, Skierski J, Turowski P, Majewska A, Polańska J, Ugorski M, Morty RE, Motyl T (2010b) Transcriptomic "portraits" of canine mammary cancer cell lines with various phenotype. J Appl Genet 51:169-183

Król M, Pawłowski KM, Majchrzak K, Dolka I, Abramowicz A, Szyszko K, Motyl T (2011) Density of tumor-associated macrophages (TAMs) and expression of their growth factor receptor MCSF-R and CD14 in canine mammary adenocarcinomas of various grade of malignancy and metastasis. Pol J Vet Sci 14:3-10

Kujawski M, Kortylewski M, Lee H, Herrmann A, Kay H, Yu H (2010) Stat3 mediates myeloid celldependent tumor angiogenesis in mice. J Clin Invest 118:3367-3377

Kusmartsev SA, Li Y, Chen SH (2000) Gr-1+ myeloid cells derived from tumor-bearing mice inhibit primary T cell activation induced through CD3/CD28 costimulation. J Immunol 165:779-785

Lee CK, Raz R, Gimeno R, Gertner R, Wistinghausen B, Takeshita K, DePinho RA, Levy DE (2002) STAT3 is a negative regulator of granulopoiesis but is not required for G-CSF dependent differentiation. Immunity 17:63-72

Lee TL, Yeh J, van Waes C, Chen Z (2006) Epigenetic modification of SOCS-1 differentially regulates STAT3 activation in response to interleukin-6 receptor and epidermal growth factor receptor signaling through JAK and/or MEK in head and neck squamous cell carcinomas. Mol Cancer Ther 5:8-19

Liang W, Kujawski M, Wu J, Lu J, Herrmann A, Loera S, Yen Y, Lee F, Yu H, Wen W, Jove R (2010) Antitumor activity of targeting Src kinases in endothelial and myeloid cell compartments of the tumor microenvironment. Clin Cancer Res 16. doi:10.1158/1078-0432.CCR-09-1486

Mazzoni A, Bronte V, Visintin A, Spitzer JH, Apolloni E, Serafini P, Zanovello P, Segal DM (2002) Myeloid Suppressor lines inhibit T cell response by an NO-dependent mechanism. J Immunol 168:689-695

Melani C, Sangaletti S, Barazzetta FM, Werb Z, Colombo MP (2007) Amino-biphosphonatemediated MMP9 inhibition breaks the tumor-bone marrow axis responsible for myeloid-derived suppressor cell expansion and macrophage infiltration in tumor stroma. Cancer Res 67:11438-11446

Mi H, Lazareva-Ulitsky B, Loo R, Kejariwal A, Vandergriff J, Rabkin S, Guo N, Muruganujan A, Doremieux O, Campbell MJ, Kitano H, Thomas PD (2005) The PANTHER database of protein families, subfamilies, functions and pathways. Nucleic Acids Res 33:D284-288

Misdorp W, Else RW, Hellemen A, Lipscomb TP (1999) Histological classification of mammary tumors of the dog and cat. Armed Forces Institute of Pathology 7:11-29 
Misdorp W (2002) Tumors of the mammary gland. In: Meuten DJ (ed) Tumours in domestic animals, 4th edn. Iowa State Press, Iowa, USA, pp 575-606

Niu G, Wright KL, Huang M, Song L, Haura E, Turkson J, Zhang S, Wang T, Sinibaldi D, Coppola D, Heller R, Ellis LM, Karras J, Bromberg J, Pardoll D, Jove R, Yu J (2002) Constitutive Stat3 activity upregulated VEGF expression and tumor angiogenesis. Oncogene 21:2000-2008

Panapoulous AD, Zhang L, Snow JW, Jones DM, Smith AM, El Kasmi KC, Liu F, Goldsmith MA, Link DC, Murray PJ, Watowich SS (2006) STAT3 governs distinct pathways in emergency granulopoiesis and mature neutrophils. Blood 108:3682-3690

Papparella S, Restucci B, Paciello O, Maiolino P (2002) Expression of matrix metalloprotease-2 (MMP-2) and the activator membrane type 1 (MT1-MMP) in canine mammary carcinomas. J Comp Pathol $126: 271-276$

Pawłowski KM, Król M, Majewska A, Badowska-Kozakiewicz A, Mol JA, Malicka E, Motyl T (2009) Comparison of cellular and tissue transcriptional profiles in canine mammary tumor. J Physiol Pharmacol 60:85-94

Pawłowski KM, Majewska A, Szyszko K, Motyl T, Król M (2011a) Gene expression pattern in canine mammary osteosarcoma. Pol J Vet Sci 14:11-20

Pawłowski KM, Popielarz D, Szyszko K, Motyl T, Król M (2011b) Growth Hormone Receptor RNA interference decreases proliferation and enhances apoptosis in canine mammary carcinoma cell line CMT-U27. Vet Comp Oncol, 9: doi. 10.1111/j.1476-5829.2011.00269.x

Pollard JW (2008) Macrophages define the invasive microenvironment in breast cancer. J Leukoc Biol 84:623-630

Potrion VA, Roche J, Drabkin HA (2003) Semaphorins and their receptors in lung cancer. Cancer Lett 273:114

Qui CW, Lin DG, Wang JQ, Li CY, Deng GZ (2008) Expression and significance of PTEN and VEGF in canine mammary gland tumours. Vet Res Commun 32:463-472

Rao NA, van Wolferen ME, Gracanin A, Bhatti SF, Król M, Holstege FC, Mol JA (2009) Gene expression profiles of progestin-induced canine mammary hyperplasia and spontaneus mammary tumors. J Physiol Pharmacol 60:73-84

Restucci B, Papparella S, Maiolino P, De Vico G (2002) Expression of vascular endothelial growth factor in canine mammary tumors. Vet Pathol 39:488-492

Schmid MC, Varner JA (2010) Myeloid cells in the tumor microenvironment: modulation of tumor angiogenesis and tumor inflammation. J Oncol. doi:10.1155/2010/201026

Wang M, Zhang W, Crisostomo P, Markel T, Meldrum KK, Fu XY, Meldrum DR (2007) STAT3 mediates bone marrow mesenchymal stem cell VEGF production. J Mol Cell Cardiol 42:1009-1015

Voronov E, Shouval DS, Krelin Y, Cagnano E, Benharroch D, Iwakura Y, Dinarello CA, Apte RN (2003) IL-1 is required for tumor invasiveness and angiogenesis. Proc Natl Acad Sci USA 100:2645-2650

Yang CH, Murti A, Pfeffer LM (1998) STAT3 complements defects in an interferon-resistant cell line: evidence for an essential role for STAT3 in interferon signaling and biological activities. Proc Natl Acad Sci 95:5568-5572

Yang L, DeBusk LM, Fukuda K, Fingleton B, Green-Jarvis B, Shyr Y, Matrisian LM, Carbone DP, Lin PC (2004) Expansion of myeloid immune suppressor Gr+CD11b+ cells in tumor-bearing host directly promotes tumor angiogenesis. Cancer Cell 6:409-421

Yang L, Huang J, Ren X, Gorska AE, Chytil A, Aakre M, Carbone DP, Matrisian LM, Richmond A, Lin PC, Moses HL (2008) Abrogation of TGFbeta signaling in mammary carcinomas recruits Gr-1+CD11b+ myeloid cells that promote metastasis. Cancer Cell 13:23-35

Youn JI, Gabrilovich DI (2010) The biology of myeloid-derived suppressor cells: the blessing and the course of morphological and functional heterogeneity. Eur J Immunol 40:2969-2975

Zetter BR (1998) Angiogenesis and tumor metastasis. Annu Rev Med 49:407-424

Zhao M, Gao FH, Wang JY, Liu F, Yuan HH, Zhang WY, Jing B (2011) JAK2/STAT3 signaling pathway activation mediated tumor angiogenesis by upregulation of VEGF and bFGF in non-small-cell lung cancer. Lung Cancer. doi:10.10.16/j.lungcan.2011.01.002 